\title{
The Ross inclusion Dacron graft
}

\author{
Jama Jahanyar, Daniel E. Muñoz, Saadallah Tamer, Gebrine El Khoury, Laurent de Kerchove
}

Department of Cardiovascular \& Thoracic Surgery, Cliniques Universitaires Saint-Luc, Université Catholique de Louvain (UCL), Brussels, Belgium Correspondence to: Laurent de Kerchove, MD, PhD. Department of Cardiovascular \& Thoracic Surgery, Cliniques Universitaires Saint-Luc, Avenue Hippocrate 10, 1200 Brussels, Belgium. Email: laurent.dekerchove@uclouvain.be.

Submitted Aug 04, 2020. Accepted for publication May 05, 2021.

doi: 10.21037/acs-2020-rp-17

View this article at: http://dx.doi.org/10.21037/acs-2020-rp-17

\section{Clinical vignette}

We present the case of a twenty-eight-year-old male with severe aortic stenosis and mean gradient across the aortic valve (AV) of $52 \mathrm{mmHg}$, due to a calcified congenital unicuspid AV. The patient was asymptomatic, without significant past medical history, and clean coronaries.

Due to extensive AV calcifications, AV repair was not feasible, and Ross procedure was indicated. Echocardiography identified a dilated aortic annulus of $28 \mathrm{~mm}$; the aortic root and ascending aorta were 34 and $40 \mathrm{~mm}$ in diameter, respectively. Following our treatment strategy for Ross procedure, Dacron-graft inclusion was the preferred technique because of young age and the dilated aortic annulus and ascending aorta.

\section{Surgical technique}

The patient is placed in supine position. The chest is entered through a midline sternotomy, and the patient is centrally cannulated. A left ventricular vent is placed through the right upper pulmonary vein. The heart is arrested with normothermic blood cardioplegia, and the ascending aorta incised and transected. The distal/anterior wall of the ascending aorta is then suspended to the skin with a 4-0 Prolene suture, three additional sutures are placed above each commissure.

The $\mathrm{AV}$ is inspected for repairability and if not amenable, is excised, and the aortic annulus completely decalcified. The pulmonary artery (PA) is opened transversely, proximal to the bifurcation, and the pulmonary valve inspected. If the valve anatomy is suitable for Ross procedure (tricuspid), the pulmonary trunk is transected and dissected from the aortic root and posteriorly from the ventricular septum.
The tip of a hemostat grabs the right ventricular muscle in the lower triangle of the anterior pulmonary commissure. The hemostat tip is then pushed through the anterior wall of the right ventricular outflow tract (RVOT), and countertraction is provided by the surgeon's hand. Starting at the point of RVOT muscle penetration, the pulmonary autograft is excised circumferentially, $3-4 \mathrm{~mm}$ proximal to the pulmonary valve, avoiding injury to the first septal branch of the left anterior descending artery. Cardioplegia is given to identify septal bleeders and hemostasis achieved.

The aortic root is prepared by opening the noncoronary sinus longitudinally, then excision of the right and left coronary buttons. We leave the distal edge of the left coronary attached to the aorta, which helps with exposure and orientation of the coronary button during reimplantation.

Cardioplegia is given every 15 minutes, via coronary artery perfusion catheters (left: 17 or $20 \mathrm{Fr}$. Medtronic DLP, Minneapolis, MN; right: 12 Fr. LivaNova, Arvada, CO).

We then secure the pulmonary autograft into a Valsalva graft. Our preferred graft is the Cardioroot Vascular Graft (Getinge, Sweden). It is sized according to the height of the pulmonary valve commissures (basal ring to tip of commissure). We generally use a $28 \mathrm{~mm}$ graft and in rare circumstances a $30 \mathrm{~mm}$ graft. The lower skirt below the Valsalva portion is removed and the tubular portion of the graft cut to accommodate the level of the distal aortic anastomosis. The autograft is placed into the graft and three commissural sutures are temporarily placed in the distal end of the Valsalva portion. The proximal autograft is secured to the graft with a running 4-0 Prolene suture. The Dacron included autograft is then parachuted to the aortic annulus with three running 4-0 Prolene sutures, commissure to commissure. 
Once seated in the LVOT at the level of the aortic annulus, the valve is inspected for prolapse. The commissures are always initially placed at the level of the neo-sinotubular junction (neo-STJ) of the Dacron graft. The distal suture attachments of the commissures to the graft, can be readjusted to acquire optimal valve geometry. Once acquired, the distal pulmonary autograft is sewn wall-to-wall to the neo-STJ of the graft with a running 4.0 Prolene locked suture.

The left coronary button is sewn to the included pulmonary autograft with a 5-0 Prolene suture. This is achieved by first incising the graft with cautery, and at the same level incising the autograft at the upper edge of the new coronary opening and pulling the lower tongue of PA tissue through the Dacron graft opening (El Khoury tongue technique). This helps with exposure and smooths the lower surface of the button anastomosis. This is important, as an unprotected raw surface of Dacron graft can damage the left coronary cusp. The right coronary anastomosis is performed in similar fashion.

A pulmonary homograft is then sewn to the distal PA, with a running 4-0 Prolene suture (small needle), and the proximal anastomosis performed with a running 4-0 Prolene suture (big needle). Aortic distal anastomosis is then completed with a running 4-0 Prolene suture at the level needed for aortic replacement. The heart is de-aired through the graft and the patient weaned off bypass and closed in standard fashion.

Importantly, assessment of autograft configuration inside the Dacron graft is performed at three stages; when the autograft is backbench sutured into the vascular graft, after the graft-reinforced autograft is sutured into the aortic annulus, and after coronary reimplantation. The commissures can be readjusted at either of the earlier two stages. Valve coaptation assessment follows the same principles as for the native AV. If we find a valve leaflet free margin below the level of the others, a prolapse is suspected. Plication of the very thin autograft cusps can be more challenging than in the native $\mathrm{AV}$, but is performed in a similar fashion with a 6-0 Prolene suture (Video 1).

\section{Comments}

The Ross procedure is a good alternative in young patients, when AV repair is not feasible. The main benefits are physiologic hemodynamics, a very low incidence of thromboembolism and endocarditis; and no need for lifelong anticoagulation. Moreover, it has the potential for further growth in children (Video 2).

However, progressive autograft dilatation in $10-30 \%$, limits long-term durability. The main risk factors are a dilated annulus with aortic regurgitation, postoperative hypertension, length and diameter of the autograft, and preexisting ascending aorta dilatation (1-3).

The pulmonary autograft inclusion into a vascular graft stabilizes the entire neo-aortic root and prevents future dilatation and aneurysm formation $(4,5)$. From 2005 to 2020, we performed 102 autograft inclusion Ross procedures (76 Cardioroot- \& 26 Valsalva-grafts), without in-hospital mortality. One patient required early reoperation and valve replacement. An additional three patients required reoperation within 5 years of follow-up. All underwent repair of their neo-AV. Both the Cardioroot- and Valsalvagraft can be utilized for reinforcement. Nonetheless, we prefer the Cardioroot-graft, finding it easier to handle, as it is slightly more rigid and the conically-shaped inflow allows for easier adjustments and additional trimming, if needed.

The Dacron-inclusion technique is one of three Ross techniques currently employed at our Center. Other techniques are the free autograft, and native aortic root inclusion. We prefer the Dacron-inclusion technique in patients with concomitant aortic annular and/or root enlargement.

There is a learning curve with this procedure. The Dacron-autograft inclusion can distort the neo-AV geometry and cause prolapse of the valve leaflets. Hence, it may be necessary to re-clamp the aorta to repair the prolapse. Nonetheless, the Dacron-graft supports the neoaortic root and aortic annulus and ameliorates possible future dilatation. To achieve good long-term results, it is important to respect the native geometry of the neo-AV. We have refined our technique over time, and herein have presented our evolved and current surgical approach.

\section{Acknowledgments}

Funding: None.

\section{Footnote}

Conflicts of Interest: The authors have no conflicts of interest to declare.

Open Access Statement: This is an Open Access article distributed in accordance with the Creative Commons Attribution-NonCommercial-NoDerivs 4.0 International 
License (CC BY-NC-ND 4.0), which permits the noncommercial replication and distribution of the article with the strict proviso that no changes or edits are made and the original work is properly cited (including links to both the formal publication through the relevant DOI and the license). See: https://creativecommons.org/licenses/by-nc-nd/4.0/.

\section{References}

1. de Kerchove L, Rubay J, Pasquet A, et al. Ross operation in the adult: long-term outcomes after root replacement and inclusion techniques. Ann Thorac Surg 2009;87:95-102.

2. Hanke T, Stierle U, Boehm JO, et al. Autograft regurgitation and aortic root dimensions after the Ross procedure:

Cite this article as: Jahanyar J, Muñoz DE, Tamer S, El Khoury G, de Kerchove L. The Ross inclusion Dacron graft. Ann Cardiothorac Surg 2021;10(4):549-551. doi: 10.21037/acs2020-rp-17 the German Ross Registry experience. Circulation 2007;116:I251-8.

3. Takkenberg JJ, van Herwerden LA, Galema TW, et al. Serial echocardiographic assessment of neo-aortic regurgitation and root dimensions after the modified Ross procedure. J Heart Valve Dis 2006;15:100-6; discussion 106-7.

4. Juthier F, Banfi C, Vincentelli A, et al. Modified Ross operation with reinforcement of the pulmonary autograft: Six-year results. J Thorac Cardiovasc Surg 2010;139:1420-3.

5. Carrel T, Schwerzmann M, Eckstein F, et al. Preliminary results following reinforcement of the pulmonary autograft to prevent dilatation after the Ross procedure. J Thorac Cardiovasc Surg 2008;136:472-5. 